\title{
Alopesi areatalı hastaların klinik ve demografik özellikleri
}

\author{
Clinical and the demographic characteristics of patients with alopecia areata
}

\author{
Sibel Yorgancılar, Ruken Azizoğlu Anlı, Roza Zelal Abdioğlu*, Mustafa Arıca** \\ Diyarbakır Eğitim ve Araștırma Hastanesi, Deri ve Zührevi Hastalıklar Kliniği, Diyarbakır, Türkiye \\ *Özel Sultan Hastanesi, Deri ve Zührevi Hastalıklar Kliniği, Diyarbakır, Türkiye \\ **Dicle Üniversitesi Tıp Fakültesi, Deri ve Zührevi Hastalıklar Anabilim Dalı, Diyarbakır, Türkiye
}

\section{Özet}

Amaç: Bu çalışmada bölgemizde görülen alopesi areatalı hastaların klinik ve demografik özelliklerinin belirlenmesi amaçlanmıştır.

Gereç ve Yöntem: Çalışmamızda Ocak-Kasım 2009 tarihleri arasında Dicle Üniversitesi Tıp Fakültesi, Deri ve Zührevi Hastalıklar Anabilim Dalı polikliniğine başvuran hastalar arasında alopesi areata tanısı alan yaşları 2-52 arasında değişen 100 hasta değerlendirildi.

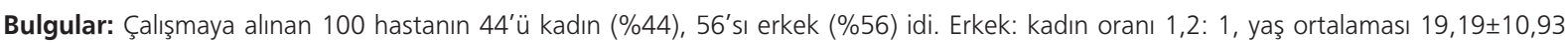
yıl idi. Hastaların 90'ında (\%90) alopesi areata, 5 'inde (\%5) alopesi totalis, $5^{\prime}$ inde (\%5) alopesi üniversalis mevcuttu. Hastaların \%64'ünde hastalığın başlangıç yaşı 20 yaş altında saptandı. Saçı deride hastaların \%77,2'sinde hafif, \%22,8'inde şiddetli tutulum tespit edildi. Saçı̆ı deride hastalık şiddeti ile cinsiyet ve hastalık başlangıç dönemi arasında anlamlı bir ilişki bulunmadı $(p=0,62, p=0,22)$. Tırnak tutulumu \%43 olarak saptandı. Tırnak tutulum tipi olarak en sık pitting $(\% 39,5)$ ve longitudinal çizgilenme $(\% 39,5)$ görüldü. Saçıl deride hastalık şiddeti ve tırnak tutulumu arasında anlamlı bir ilişki bulunmadı $(p=0,08)$. Hastaların $\% 22$ 'sinde aile hikayesi mevcuttu. Aile hikayesi ile hastalığın başlangıç dönemi ve saçlı deride hastalık şiddeti arasında anlamlı bir ilişki bulunmadı ( $p=0,13, p=0,07)$.

Sonuç: Çalışmamızın sonuçları daha önce yapılan klinik ve demografik çalışmaların verileriyle uyumlu bulunmuştur. (Türkderm 2013; 47: 155-7) Anahtar Kelimeler: Alopesi areata, demografik özellikler, klinik özellikler

\section{Summary}

Background and Design: In this study, our aim was to determine clinical and demographical characteristics of patients with alopecia areata in our region.

Materials and Methods: In the study, we evaluated 100 patients (44 female, 56 male; age range: 2-52 years) who applied to the outpatient clinic of Dicle Medical Faculty Dermatology Department between October and November 2009 and received the diagnosis of alopecia areata. Results: The male:female ratio was 1.2:1, the mean age was $19.19 \pm 10.93$ years. Alopecia areata was present in 90 (90\%) patients, alopecia totalis in $5(5 \%)$, and alopecia universalis in $5(5 \%)$ patients. The age of the disease onset was below the age of 20 years in $64 \%$ of patients. In $77.2 \%$ of patients, mild and in $22.8 \%$ of patients, severe scalp involvement was detected. There was no significant relationship of the severity of the disease in the scalp with gender and the disease onset period $(p=0.62, p=0.22)$. Nail involvement was detected in $43 \%$, mostly as pitting (39.5\%) and longitudinal ridging (39.5\%). No significant relationship was found between disease severity in the scalp and nail involvement $(p=0.08)$. A family history was present in $22 \%$ of patients. There was no significant relationship of family history with the onset period of the disease and the disease severity in the scalp $(p=0.13, p=0.07)$.

Conclusion: Our results were found to be consistent with the clinical and demographic data obtained in previous studies. (Turkderm 2013; 47: 155-7) Key Words: Alopecia areata, demographic characteristics, clinical characteristics

Yazışma Adresi/Address for Correspondence: Dr Sibel Yorgancılar, Diyarbakır Eğitim ve Araştırma Hastanesi, Deri ve Zührevi Hastalıklar Kliniği, Diyarbakır, Türkiye Tel.: +90 4122580060 E-posta: drsibel80@hotmail.com Geliş Tarihi/Received: 09.10.2012 Kabul Tarihi/Accepted: 17.12.2012 


\section{Giriş}

Alopesi areata (AA), vücutta kıllı herhangi bir alanı etkileyen, skarsız kıl kaybı ile kendini gösteren, kıl folikülünün $T$ lenfositler aracılığıyla oluşan otoimmün, organ spesifik bir hastalığıdır1,2.

Alopesi areatalı hastaların klinik ve demografik özelliklerini inceleyen yayınlar literatürde mevcuttur. Ancak bölgemiz hastalarını içeren çalışmalar bildiğimiz kadarıyla mevcut değildir. Çalışmamızın amacı bölgemizdeki $\mathrm{AA}^{\prime}$ lı hastaların klinik ve demografik özelliklerini incelemek, ayrıca hastalık şiddeti ile klinik bulgular arasındaki ilişkileri değerlendirmektir.

\section{Gereç ve Yöntem}

Ocak- Kasım 2009 tarihleri arasında Dicle Üniversitesi Tıp Fakültesi, Deri ve Zührevi Hastalıklar Anabilim Dalı polikliniğine başvuran hastalar arasında AA tanısı almış yaşları 2-52 arasında değişen 44'ü kadın 56'sı erkek olan 100 hasta ardışı olarak seçilerek çalışmaya alındı. Hastalardan $\leq 16$ yaşında olanlar çocuk hasta olarak değerlendirildi.

Değerlendirmeye alınan hastaların yaşları, cinsiyetleri, alopesi tutulum alanları (saç, sakal, kaş, kirpik, diğer vücut kılları), mevcut atağın süresi (<1 yıl , $\geq 1$ yıl) hastalığın başlangıç yaşı, saçtaki lokalizasyon yeri (oksipital, paryetal, temporal, frontal, verteks), nevus flammeus varlığı, subjektif semptom varlığı (kaşıntı, yanma, ağrı, parestezi), tırnak tutulumu varlığı ve tipi ("pitting", longitudinal çizgilenme, lökonişi, trakionişi, tırnak plağında incelme veya kalınlaşma, Beau çizgisi, koilonişi, onikoreksis, onikomadezis, kırmızı noktalı lunula) kaydedildi. Ailede AA hikayesi sorgulandı.

Hastalar klinik olarak AA, alopesi totalis ve alopesi üniversalis olarak ayrıldı. Saçlı deri tutulumu olan AA'lı hastalarda tutulum tipleri (yama, retiküler, ofiyazis, sisaipho, diffüz) kaydedildi.

Saçlı deri tutulumu olan 88 hastanın kıl kaybı yüzdesi SALT (Severity of Alopecia Tool) ${ }^{3}$ skoruna göre değerlendirildi. Sonrasında SALT skoruna göre kıl kaybı yaygınlığı gruplandırıldı. Buna göre kıl kayıpları; $\mathrm{S} 1=<\% 25, \quad \mathrm{~S} 2=\% 25-49, \mathrm{~S} 3=\% 50-74, \quad \mathrm{~S} 4=\% 75-99 \quad(a=\% 75-95$, $\mathrm{b}=\% 96-99)$ ve $\mathrm{S} 5=\% 100$ olarak değerlendirildi.

Saçlı derideki hastalık şiddeti hafif $(\mathrm{S} 1, \mathrm{~S} 2)$ ve şiddetli $(\mathrm{S} 3, \mathrm{~S} 4, \mathrm{~S} 5)$ olarak gruplandırıldı. Veriler SPSS 16.0 programında değerlendirildi ve $x^{2}$ (Chi Square) istatistik metodu ile analiz edildi. Analiz sonucunda $p<0,05$ değeri anlamlı, p>0,05 değeri anlamsız olarak kabul edildi.

\section{Bulgular}

Çalışmadaki hastaların 44'ü kadın (\%44), 56'sı erkekti (\%56) (oranı

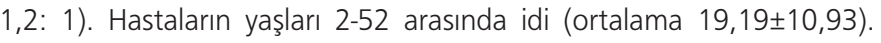

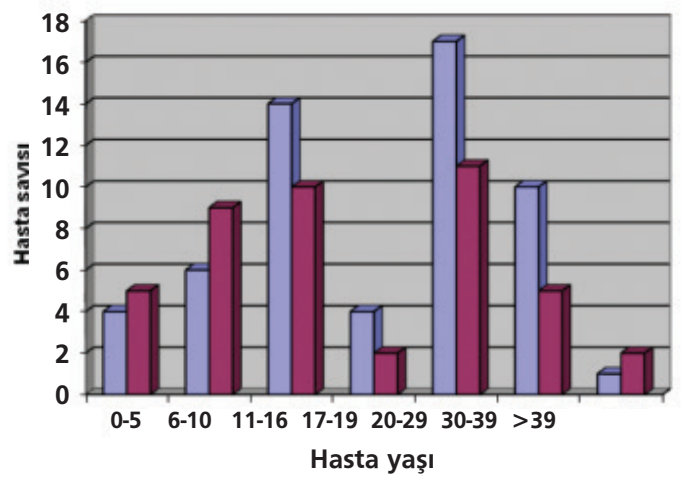

口erkek

akadın

Şekil 1. Alopesi Areatalı hastaların yaş ve cinsiyet dağılımı
Hastaların 48'i çocuk ( $\leq 16$ yaş), 52'si erişkin (>16 yaş), \%97'si 40 yaş altında idi (Şekil 1).

Hastalardan 90'ında (\%90) AA, 5'inde (\%5) alopesi totalis, 5'inde (\%5) alopesi üniversalis mevcuttu. Klinik olarak AA saptanan 90 hastanın 78 'inde saçlı deri tutulumu vardı. Saçlı deri tutulumu olan 78 hastanın alopesi tiplerine bakıldığında 58 hastada $(\% 74,3)$ yama, 19 hastada $(\% 24,4)$ ofiyazik ve 1 hastada $(\% 1,3)$ retiküler tip tespit edildi.

Hastalarda hastalığın başlangıç yaşı 2-42 yaş arasında değişmekte olup, ortalama 16,06 $\pm 9,49$ yıl olarak tespit edildi. Hastaların \%64'ünde hastalığın başlangıç yaşının 20 yaşın altında olduğu saptandı.

Hastaların hastalık başlangıç yaşı çocukluk dönem ( $\leq 16$ yaş) ve erişkin dönem (>16 yaş) olarak ayrıldı. Buna göre hastaların \%56'sının hastalık başlangıç yaşı çocukluk, \%44'nün erişkinlik dönemde olduğu tespit edildi. Kadın hastaların 27'sinde (\%61), erkek hastaların 29'unda (\%51) hastalığın çocukluk döneminde başladığı tespit edildi. Hastaların cinsiyetleri ile hastalık başlangıç yaşları (çocukluk ve erişkinlik dönemi) arasında yapılan karşılaştırma sonrası istatistiksel olarak anlamlı bir ilişki bulunmadı $(p=0,46)$.

Tutulum alanına bakıldığında 88 hastada (\%88) saçı deri, 23 hastada sakal (\%23), 25 hastada (\%25) kaş, 15 hastada (\%15) kirpik ve 17 hastada (\%17) diğer vücut kıllarında dökülme (aksilla, ekstremiteler, pubik bölge) mevcuttu. Sadece saçı deri tutulumu 54 hastada (\%54), sadece sakal tutulumu 9 hastada (\%9), sadece kaş-kirpik tutulumu 2 hastada (\%2) mevcuttu. Saçlı deri tutulumu olan hastalarda saçtaki lokalizasyona göre en sık oksipital bölgede $(\% 82,9)$ tutulum görüldü. Hastaların atak süresi değerlendirildiğinde; \%82'sinin mevcut atak süresi 12 ayın altında (<1yıl), \%18'inin mevcut atak süresi 12 ay ve üstünde ( $\geq 1$ yıl) saptandı.

Saçlı deri tutulumu olan 88 hastada tutulum yaygınlığı SALT skoruna göre gruplandırıldı (Tablo 1). Saçlı derideki hastalık şiddeti değerlendirildiğinde, hastaların 68'inde $(\% 77,2)$ hafif $($ S1,S2), 20 'sinde $(\% 22,8)$ şiddetli hastalığın $(\mathbf{S} 3, \mathbf{S} 4, \mathbf{S} 5)$ olduğu tespit edildi (Tablo 2$)$. Saçlı deride hastalık şiddeti ile cinsiyet karşılaştııılığında istatistiksel olarak anlamlı bir ilişki bulunmadı $(p=0,62)$.

Saçlı deride hafif tutulumu olan hastaların 38'inde (\%56), şiddetli tutulumu olan hastaların 15'inde (\%71) hastalığın çocukluk döneminde başladığı saptandı. Saçlı deride hastalık şiddeti ile hastalık başlangıç dönemi (çocukluk ve erişkinlik dönem) karşılaştııılığında istatistiksel olarak anlamlı bir ilişki bulunmadı $(p=0,22)$.

Tablo 1. Alopesi areatalı hastaların Severity of Alopecia Tool (SALT) skoruna göre dağılımı

\begin{tabular}{|c|c|c|c|c|}
\hline SALT skoru & $\begin{array}{c}\text { Kadın } \\
(\mathbf{n = 4 2 )}\end{array}$ & $\begin{array}{c}\text { Erkek } \\
\mathbf{( n = 4 6 )}\end{array}$ & $\begin{array}{c}\text { Toplam } \\
(\mathbf{n = 8 8})\end{array}$ & Yüzde (\%) \\
\hline S1 & 24 & 29 & 53 & 60,2 \\
\hline S2 & 8 & 7 & 15 & 17 \\
\hline S3 & 1 & 4 & 5 & 5,7 \\
\hline S4 & 4 & 1 & 5 & 5,7 \\
\hline S5 & 5 & 5 & 10 & 11,4 \\
\hline
\end{tabular}

Tablo 2. Alopesi areatalı hastaların saçlı deride

hastalık şiddetine göre dağılımı

\begin{tabular}{|l|l|l|l|l|}
\hline Hastalık şiddeti & $\begin{array}{l}\text { Kadın } \\
(\mathbf{n = 4 2 )}\end{array}$ & $\begin{array}{l}\text { Erkek } \\
(\mathbf{n = 4 6 )}\end{array}$ & $\begin{array}{l}\text { Toplam } \\
(\mathbf{n = 8 8})\end{array}$ & Yüzde (\%) \\
\hline Hafif & 31 & 36 & 67 & 77,2 \\
\hline Şiddetli & 11 & 10 & 21 & 22,8 \\
\hline
\end{tabular}


Saçlı deri tutulumu olan hastalarda nevus flammeus değerlendirildi. Hastaların 10'unda $(\% 11,4)$ nevus flammeus mevcuttu. Hastaların 29 'unda (\%29) alopesik alanlarda subjektif şikayet bulunmaktaydı. Şikayeti olan hastalarda en sık görülen, kaşıntı şikayeti olup 24 hastada $(\% 82,7)$ mevcuttu.

Hastalarda tırnak tutulumu değerlendirildiğinde, 43 hastada (\%43) tırnak tutulumu tespit edildi. Tırnak tutulumu olan hastalardan 17 hastada $(\% 39,5)$ pitting, 17 hastada $(\% 39,5)$ longitudinal çizgilenme, 13 hastada $(\% 30,2)$ lökonişi, 3 hastada $(\% 6,9)$ trakionişi ve 2 hastada $(\% 4,6)$ tırnak plağında kalınlaşma tespit edildi. Saçlı deride hafif tutulumu olan hastaların 27'sinde (\%40), şiddetli tutulumu olan hastaların 13'ünde (\%62) tırnak tutulumu saptandı. Saçlı deride hastalık şiddeti ve tırnak tutulumu karşılaştırılığında istatistiksel olarak anlamlı bir ilişki saptanmadı $(p=0,08)$.

Ailede AA hikayesi sorgulandı. Hastaların 22'sinde (\%22) aile hikayesi mevcuttu. Aile hikayesi olan hastaların 9'unda (\%41), aile hikayesi olmayan hastaların 46'sında (\%58) hastalığın çocukluk döneminde başladığı saptandı. Aile hikayesi ile hastalığın başlangıç dönemi arasında anlamlı bir ilişki saptanmadı $(p=0,13)$. Saçlı derideki hastalık şiddeti ile aile hikayesi arasındaki ilişki değerlendirildiğinde, hafif tutulumu olan hastaların 19'unda (\%28), şiddetli tutulumu olan hastaların 2'sinde $(\% 9,5)$ aile hikayesi saptandı. Aile hikayesi ile saçlı deride hastalık şiddeti arasında anlamlı bir ilişki bulunmadı $(p=0,07)$.

\section{Tartışma}

Alopesi areata ırk, cins ve yaş ayırımı yapmadan herkeste görülebilir. Genel olarak kadın ve erkeklerde eşit oranda görülür1,4. Ancak bazı çalışmalarda kadınlarda, bazılarında ise erkeklerde daha fazla oranda görüldüğü bildirilmiştir5-8. Ülkemizde yapılan çalışmalarda da benzer dağılımlar bulunmuştur9,10. Bizim çalışmamızda ise erkeklerde görülme oranı hafif düzeyde fazla bulundu.

Yapılan çalışmalarda AA'nın büyük çoğunluğunun 40 yaş altında görüldüğü bildirilmiştir6,8. Bizim çalışmamızda literatürle uyumlu olarak hastaların \%97'sinin 40 yaş altında olduğu saptanmıştır.

Hastaların çoğunda başlangıç hayatın ilk 3 on yılı içinde görülmekle birlikte AA herhangi bir yaşta başlayabilir11. Yapılan çalışmalarda hastaların \%37,6 ile \%48'inde başlangıç yaşı 20 yaş altında bulunmuştur8,12. Bizim çalışmamızda hastaların \%64'ünde başlangıç yaşı 20 yaş altında tespit edilmiş olup bu oran yukarıdaki çalışmalara göre daha yüksektir.

Hastalığın başlangıç dönemi ile cinsiyeti karşılaştıran çalışmalar da mevcuttur. Ülkemizdeki bir çalışmada çocukluk döneminde hastalık başlangııının kadınlarda erkeklere göre daha yüksek oranda olduğu bildirilmiştir ${ }^{10}$. Bizim çalışmamızda hastaların cinsiyetleri ve hastalık başlangıç dönemleri arasında anlamlı bir farklılık bulunmamıştır.

Alopesi areata tiplerinden yama tipi, en sık görülen AA tipidir1,13. Bizim çalışmamızda da en sık yama tipi saptanmıştır.

Alopesi areata her türlü kıllı bölgeyi tutsa da en sık sırasıyla saçlı deri, sakal, ekstremite ve kaş tutulumu görülmektedir8,10,14. Bizim çalışmamızda da en sık tutulum saçlı deride iken literatürle farklı olarak ikinci sıklıkta kaş tutulumu gözlemledik.

Saçlı deride tutulum bölgesi olarak en sık oksipital daha sonra paryetal bölge tutulumu olduğu bildirilmiştir15. Ülkemizde yapılan bir çalışmada en sık sırasıyla; oksipital, verteks, paryetal, temporal ve frontal bölgede tutulum bildirilmiştir10. Bizim çalışmamızda da hastaların büyük çoğunluğunda oksipital bölgede tutulum görüldü.

Cinsiyet ile hastalık şiddeti arasındaki ilişkiyi karşılaştıran çalışmalar da mevcuttur. Bir çalışmada kadınlarda erkeklere göre daha şiddetli tutulumun görüldüğü bildirilmiştir5. Ülkemizde yapılan başka bir klinik çalışmada ise cinsiyet ile hastalık şiddeti arasında anlamlı bir ilişki bulunmamıştır. Ayrıca bu çalışmada hastalığın başlangıç dönemi (çocukluk, erişkinlik dönem) ile hastalık şiddeti de karşılaştırılmış ve anlamlı bir ilişki bulunmamıştır ${ }^{10}$. Bizim çalışmamızda da hem cinsiyet ve saçlı deride hastalık şiddeti arasında hem de hastalık şiddeti ve başlangıç dönemi (çocukluk, erişkinlik dönem) arasında anlamlı bir ilişki saptanmadı.

Alopesi areatalı vakalarda \%7-66 oranında tırnak tutulumu görülebilir 16 . En sık gözlenen bulgu ise "pitting"dir8. Bizim çalışmamızda hastaların $\% 43$ 'inde tırnak tutulumu olup, en sık "pitting" ve longitudinal çizgilenme görüldü. Ayrıca saçlı deride hastalık şiddeti ve tırnak tutulumu arasında istatistiksel olarak anlamlı bir ilişki saptanmadı.

Alopesi areatalı hastalarda pozitif aile hikayesi sıklığı \%10-20 arasındadır14,17. Ancak bu sıklık daha yüksek de olabilmektedir14,10,18 Bazı çalışmalarda aile hikayesi ile hastalık şiddeti arasındaki ilişki karşılaştııımış anlamlı bir ilişki bulunamamıştır ${ }^{10,18}$. Bizim çalışmamızda hastaların \%22'sinde aile hikayesi mevcuttu. Çalışmamızda hem aile hikayesi ile hastalığın başlangıç dönemi arasında hem de saçlı deride hastalık şiddeti ile aile hikayesi arasında da istatistiksel olarak anlamlı bir ilişki bulunamadı.

Sonuç olarak bölgemizdeki AA'lı hastaların klinik ve demografik verileri diğer çalışmalar ile uyumlu bulunmuştur. Ancak bu konuda net sonuçlar ortaya koymak için daha fazla sayıda hasta içeren çok merkezli çalışmalara intiyaç vardır.

\section{Kaynaklar}

1. Madani S, Shapiro J: Alopecia areata update. J Am Acad Dermatol 2000;42:549-66.

2. Gilhar A, Kalish RS: Alopecia areata: a tissue specific autoimmüne disease of the hair follicle. Autoimmün Rev 2006;5:64-9.

3. Olsen E, Hordinsky M, McDonald-Hull S, et al: Alopecia areata investigational assessment guidelines. National Alopecia Areata Foundation. J Am Acad Dermatol 1999;40:242-6.

4. Berger TG, Odom BR, James WD: Andrew's Diseases of the skin. 9th ed. Philadelphia: WB Saunders, 2000;943-90.

5. Tan E, Tay YK, Goh CL, Chin Giam Y: The pattern and profile of alopecia areata in Singapore-a study of 219 Asians. Int J Dermatol 2002;41:748-53.

6. Guzmán-Sánchez DA, Villanueva-Quintero GD, Alfaro Alfaro N, McMichael A A clinical study of alopecia areata in Mexico. Int J Dermatol 2007;46:1308-10.

7. Goh C, Finkel M, Christos PJ, Sinha AA: Profile of 513 patients with alopecia areata: associations of disease subtypes with atopy, autoimmüne disease and positive family history. J Eur Acad Dermatol Venereol 2006;20:1055-60

8. Sharma VK, Dawn G, Kumar B: Profile of alopecia areata in Northern India. Int J Dermatol 1996;35:22-7.

9. Kılınç I, Alper S, Ceylan C, Ünal i̇: Alopesi areatalı olgularda hasta profili: Bir retrospektif çalışma. Ege Tıp Dergisi 2002;41:25-7.

10. Kavak A, Yeşildal N, Parlak AH, et al: Alopecia areata in Turkey: demographic and clinical features. J Eur Acad Dermatol Venereol 2008;22:977-81.

11. Olsen EA, Paus R, Messenger AG: Hair growth disorders. In: Fitzpatrick's Dermatology in General Medicine. Wolff K, Goldsmith LA, Katz SI, et al, eds. $7^{\text {th }}$ ed. New York: Mc Graw Hill, 2008;762-5.

12. Shellow WV, Edwards JE, Koo JY: Profile Profile of alopecia areata: a questionnaire analysis of patient and family. Int J Dermatol 1992;31:186-9.

13. Shapiro J, Madani S: Alopecia areata: diagnosis and management. Int J Dermatol 1999:38(Suppl 1):19-24.

14. Berker DAR, Messenger AG, Sinclair RD: Disorders of hair. In: Rook's Textbook of Dermatology. Burns T, Breathnach S, Cox N, Griffiths C, eds. 7th ed. Oxford: Blackwell Science, 2004;63.1-63.120.

15. Jain S, Marfatia YS: Alopecia areata-pattern in industrial city of Baroda. Indian J Dermatol Venereol Leprol 2003;69:81-2.

16. Alkhalifah A, Alsantali A, Wang E, McElwee KJ, Shapiro J: Alopecia areata update: part I. Clinical picture, histopathology, and pathogenesis. J Am Acad Dermatol 2010;62:177-88.

17. Al-Mutairi N, Eldin ON: Clinical profile and impact on quality of life: seven years experience with patients of alopecia areata. Indian J Dermatol Venereol Leprol 2011;77:489-93.

18. Nanda A, Al-Fouzan AS, Al-Hasawi F: Alopecia areata in children: a clinical profile. Pediatr Dermatol 2002;19:482-5. 